\title{
Factor II Inactivation
}

National Cancer Institute

\section{Source}

National Cancer Institute. Factor II Inactivation. NCI Thesaurus. Code C131661.

Presence of inactivating antibodies to prothrombin (factor II) in the blood. 